\title{
TEXTILES AND POTTERY OF TAGUA TAGUA
}

\author{
Max Sepulveda
}

\section{INTRODUCTION}

During the 18 years of my career, I have worked in many places in Chile and Latin America, researching and depicting in textiles, pottery, murals and audiovisuals the sociocultural themes, the natural and cultural heritage of the land and its communities, and generating in this way a narrative, a creation, and a collective as well as collaborative generation of artistic processes.

As a specialist in collaborative art, a kind of contemporary art linked to social work, I use the methodology of activeparticipative work whereby I produce artistic work with the community, inspired by the processes of collective social reflection on questions of context, reality and issues relating to land. Such projects are potentially very significant for the community and, conversely, local practices can be reconfigured as a source of inspiration for experimental artworks.

Working together with the community in a horizontal fashion generates moments of reflection about the reality of the land and its communities. My main strategy is to develop knowledge exchange, role-playing and collective cooperation, the facilitation of a humanising experience where love, respect and mutual support is fundamental. Dialogues with the community occur through a process of social thinking, encompassing issues such as respect, empathy, solidarity and cooperativism, and the willingness to address problems of coexistence in community, among other things. In this way the community can open up about their shortcomings, dreams, hopes, socio-environmental conflicts, the onslaughts of nature, support networks, future projects, heritage issues, characteristics and history, among other themes related to the land, via the participative project. In turn, they also become a source of inspiration for a variety of collective artworks. Through the various processes of creation and collaborative production involved, this practice aims to raise awareness of the importance of social organisation, empowerment, critique and the collective assessment of the experiences, processes and results involved.

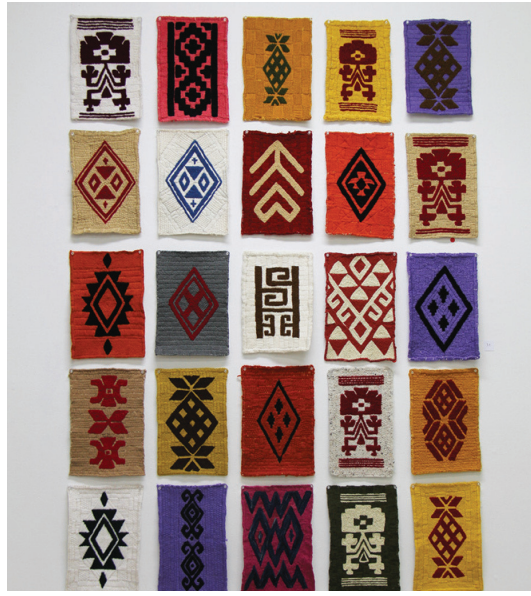

Figure I.Traditional embroidered designs.

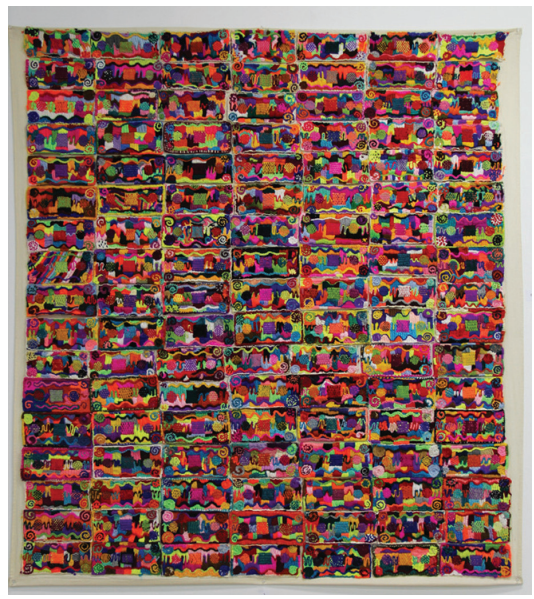

Figure 2. Composite panel made from many smaller embroidered pieces. 


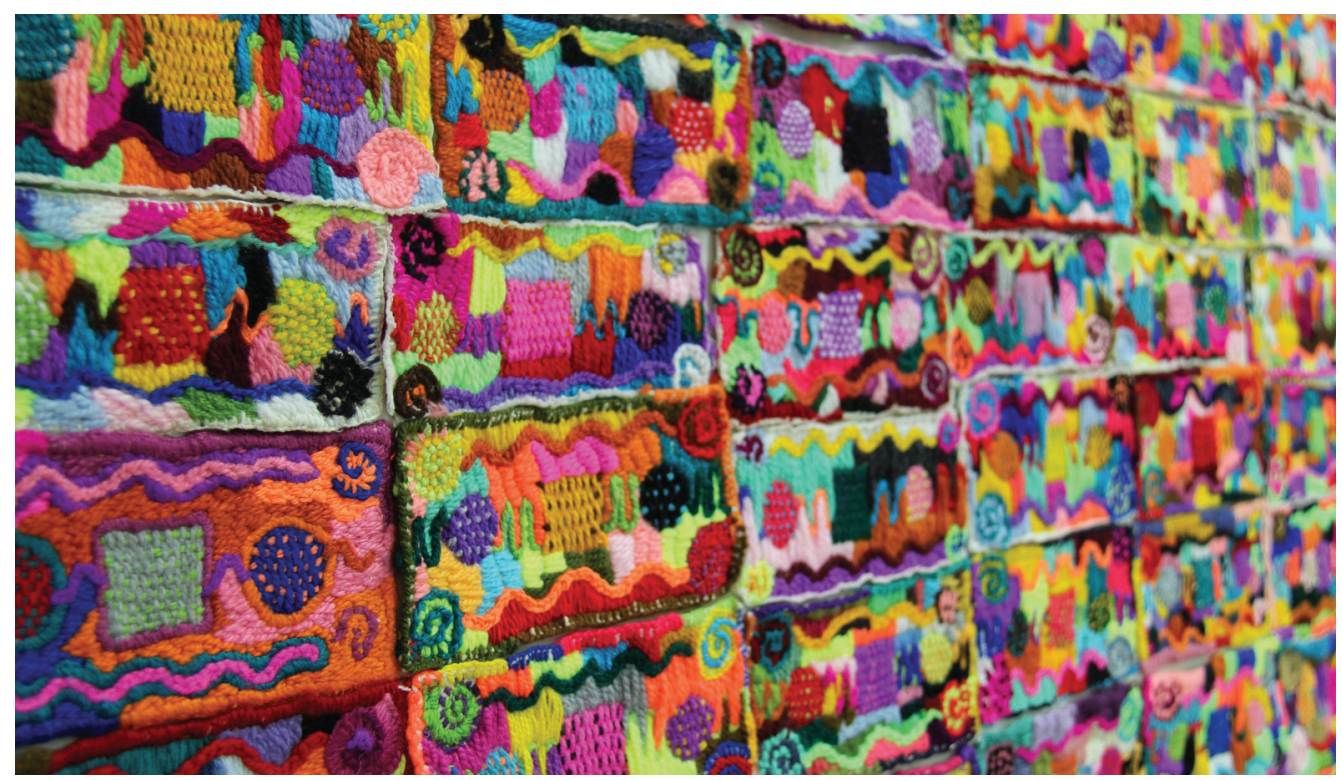

Figure 3. Detail of composite panel made from many smaller embroidered pieces.
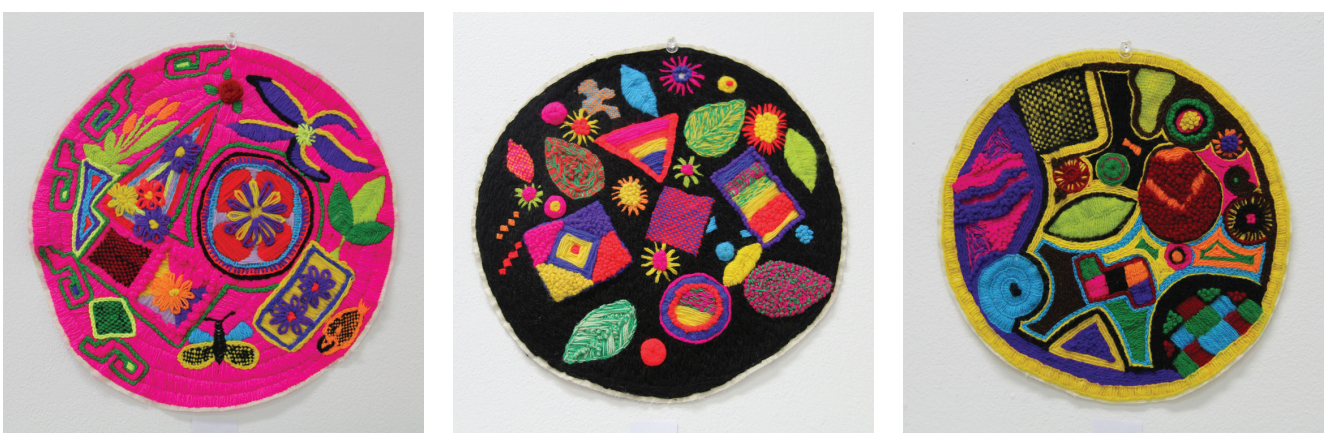

Figure 4. Circular embroideries.

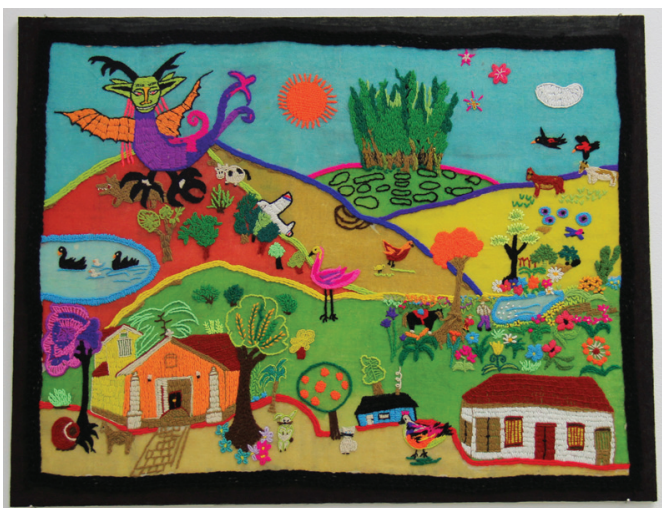

Figure 5. Embroidered scene.

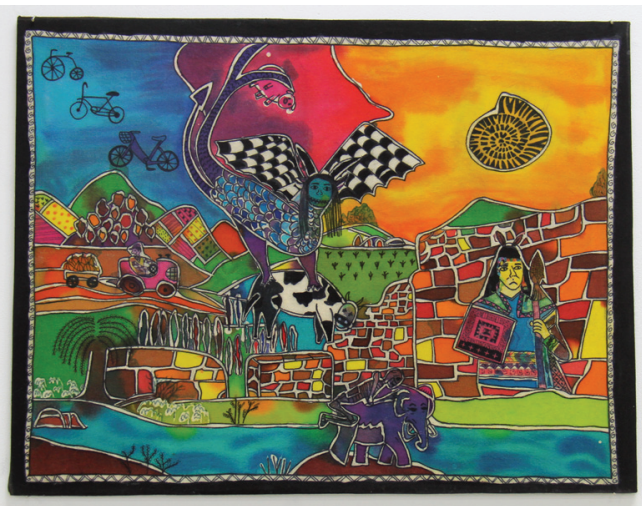

Figure 6. Batik scene. 


\section{CONTEXTUALISATION OF THE “TEXTILES AND POTTERY EXHIBITION OF TAGUA TAGUA”}

The textile exhibition was made up of creations by the author plus a selection of collaborative creations inspired by the characteristics and natural and cultural patrimony of the commune of San Vicente de Tagua Tagua in Central Chile. The collaborative works were created with the community, following processes involving collective reflection and experimentation with drawing, painting and textile techniques with a group of more than 120 people. The textile techniques that were applied in these ornamental and utilitarian creations were batik, embroidery, macramé, Mapuche loom and Mayan loom.

For the exhibition, the textile symbols of the Mapuche native people and their cosmogonic meanings were recreated in weaves and embroideries. The Lukütüwe is an anthropomorphic symbol that symbolises the human being in an attitude of prayer to the god Ngenechén (Fig. I). The Chakana symbol of power is used by the Lonko or head of a tribe (Fig. 2). The Nge Nge is a symbol representing a pair of eyes that scrutinise the soul (Fig. 3). The symbol of the Wangülen represents the southern cross star cluster that guides voyagers (Fig. 4). The design known as the Añumka represents a medicinal plant (Fig. 5). The Maüñimin represents the tribal unit of the Mapuche communities (Fig. 6). The design known as Pichikemenküe represents the conservation of food in jars of clay (Fig. 7). The design called Willodmawe Nimin symbolises the creation of the world through the strife between two sacred serpents, Tren Tren Vilú and Cai Cai Vilú (Fig. 8).

In addition to the textile exhibition, pieces of ancestral style pottery were exhibited. These were inspired by preColumbian pottery found in the Cachapoal River basin of Central Chile. The found pieces dated from the early pottery period ( $800 \mathrm{BC}$ to $900 \mathrm{AD}$ ). At least three cultural units have been defined within this period: the initial pottery communities of Bato and Llolleo and, later, the Aconcagua cultural complex. Throughout the Cachapoal River basin we find fascinating archaeological remains of pottery showing the influence of the Mapuche, Diaguita, Inca, Atacama and Viluco peoples from the eastern slope of the Los Andes mountain range, native peoples who coexisted and visited Central Chile before the arrival of the Spaniards. Their figures spanned the range from anthropomorphic, zoomorphic and fitomorphic forms, with simple decorations that remind us of the minimalism of rock art, to the geometric and other complex forms that represent the worldview of the peoples responsible.

The archaeological vestiges of pottery from the Cachapoal basin include utilitarian objects as well as magicoreligious objects and ceremonial offerings. The Chakana, a millenary symbol, is a synthesis of the Andean worldview, as well as an astronomical concept linked to the seasons of the year and a philosophical and scientific conception, drawn on by all the pre-Columbian cultures that inhabited the region from Mexico to Chile - not only in pottery, but also in textiles, basketry, goldsmithing and architectural decoration.

A fundamental part of my artist residency was conducting experiments in the Ceramic Studio at the School of Art, an opportunity that allowed me to explore a new way of decorating my pottery production, using minimalist and traditional modes. At the beginning of the process of experimenting with traditional modeling techniques, I was influenced by the shapes and decorations of the pre-Columbian vessels of my homeland, the ceremonial pipes and the bowls or plates. Later, after learning of the death of my ex-partner in Argentina, my work was dedicated to his memory, inspiring me to create a series of two two-dimensional works and a three-dimensional one.

The works created during my residency underwent different processes of burnishing and decoration, some on damp and semi-dry clay using relief, glaze paint and glaze techniques, as well as decoration with dyes oxides or enamels applied by immersion on cooked ceramics; in other cases, I used sgraffito of the slip on the semi-dry clay. For these processes of ceramic experimentation I was guided by the students in the Ceramic Studio, allowing me to create for the first time a polycolorised and brilliant piece that reflects the influence of the Latin American colour palette, mingled with emotions, memories and personal experiences, as well as a mix of traditional pottery techniques with ceramic technology. A significant portion of the works created during my residency will soon be exhibited in my home region of Chile, crowning my enriching experience of working at the Dunedin School of Art, on the other side of the Pacific Ocean. 

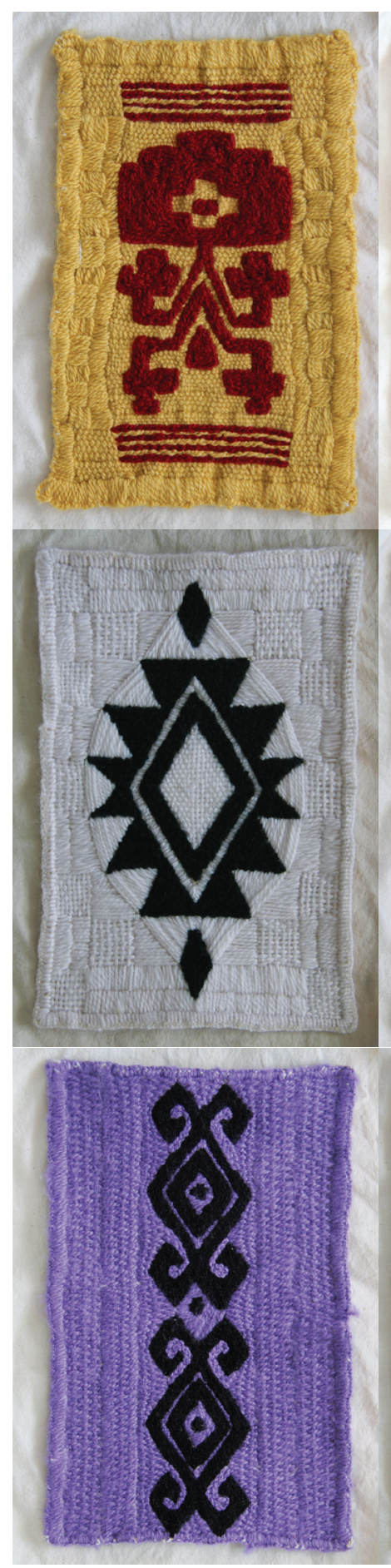
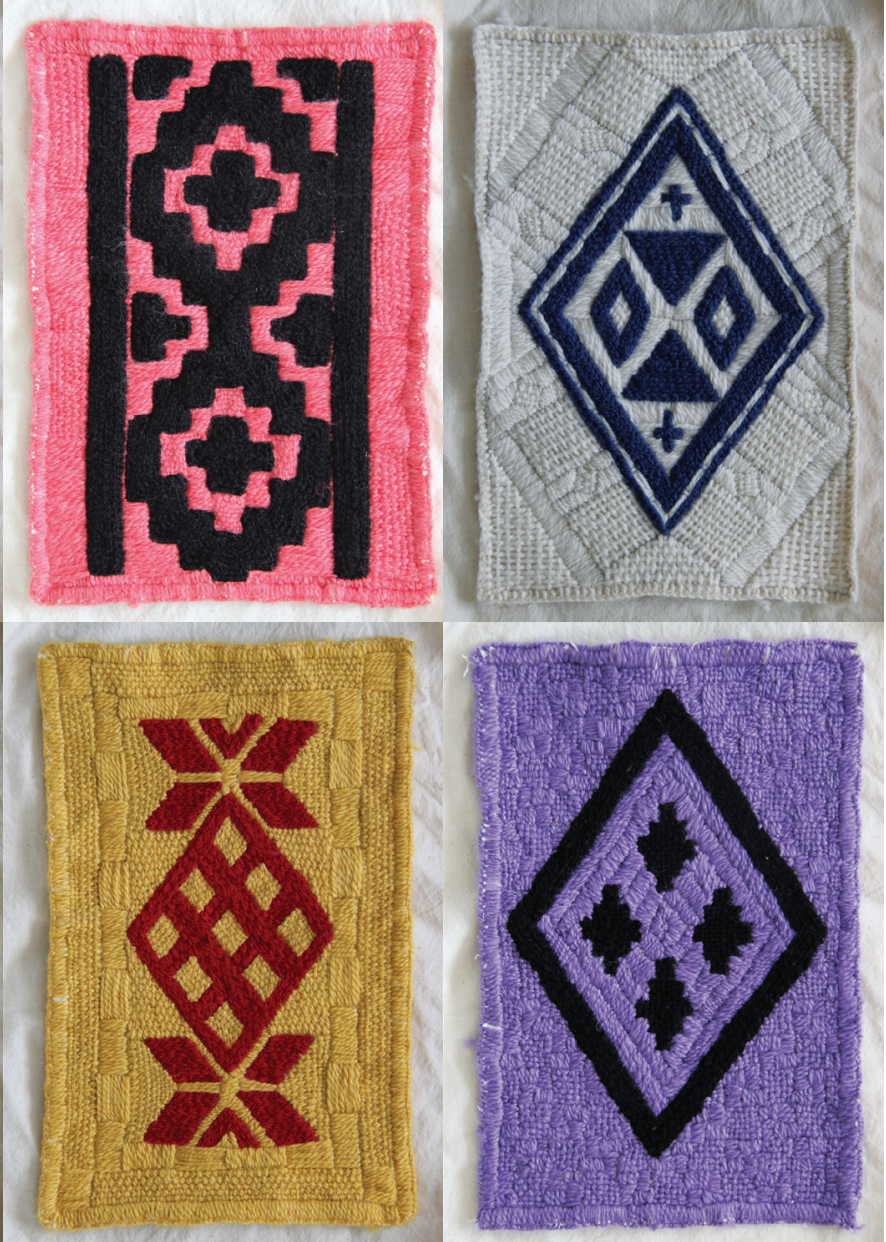

Figure 7. Composite image of traditional Mapuche designs from top left:

(I) Lukütüwe

(2) Chakana

(3) Nge Nge

(4) Wangülen

(5) Añümka

(6) Maüñimin

(7) Pichikemenküe

(8) Willodmawe Ñimin. 
My creations in clay are thin-walled, sometimes very polished, sometimes with unpolished contrasts. I use both the form-up and the form-down techniques to decorate, as well as mamelons, grips and ears. The forms I use are somewhat asymmetrical, sometimes minimalist, sometimes more recharged. The most common incisions I use are straight lines and curves; sometimes the polishing is smooth or combined with simple prints of round objects. My pottery is very organic and made with basic stone, wood and metal tools, so that one can see the traces of what was handmade - and inspired by the original pieces of pre-Columbian pottery from the Cachapoal River basin of Central Chile.

\section{PUBLIC WORKSHOPS ON ANCESTRAL POTTERY AT THE DUNEDIN SCHOOL OF ART AND THE HUB AT OTAGO POLYTECHNIC}

As part of my residency, public workshops at the Dunedin School of Art were offered in ancestral pottery using the Mapuche method, which is characterised by the use of coils in the creation of the pieces and hand modeling with basic tools, followed by the firing of the pieces with cow and horse dung in a campfire. More than 30 people participated in this event, which was held in the ceramics workshop at the Art School and in the Hub at Otago Polytechnic. It involved art students and staff, and students from other fields who were keen to try this pottery method. This was an opportunity to have an experience where we connected through artistic practices to share, create a collective pedagogy, socialise, meet new people, experience new cultures, generate spaces for dialogue, contribute to social cohesion, and enjoy the therapeutic qualities of pottery by connecting with the four elements of nature: earth, water, air and fire.
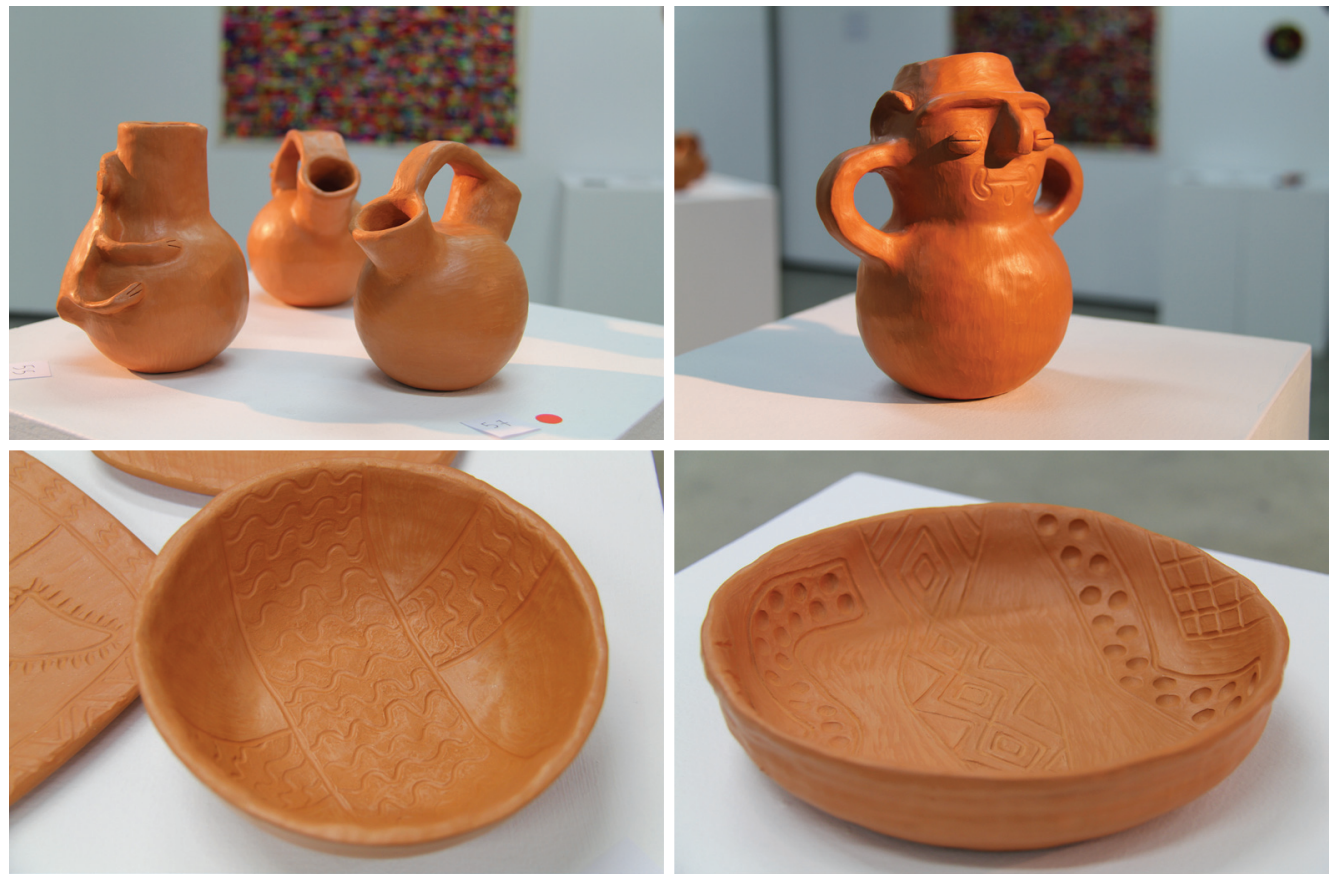

Figure 8. Installation view of hand built ceramics from Exhibition. 

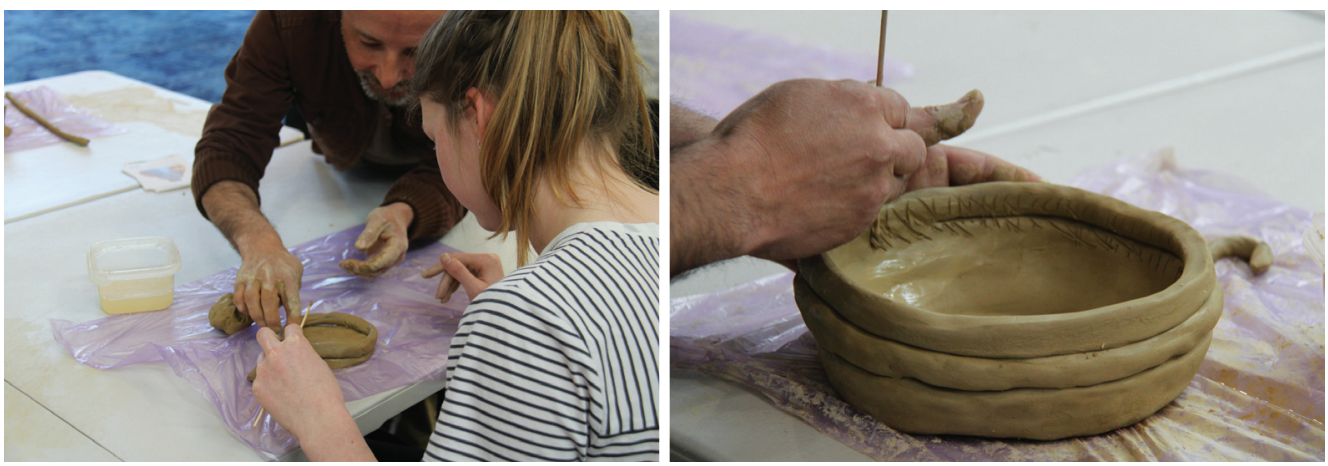

Figure 9. Public workshops were offered in ancestral pottery using the Mapuche method, hand modeling with basic tools.

For me, the artist residency offered a great opportunity to share my knowledge and to help raise participants' selfesteem by teaching them new skills and utilising this type of artistic intervention to contribute to social transformation through art. Working in distant latitudes was an opportunity to create a cultural diffusion of contemporary Chilean handicrafts and above all a great opportunity to acquire new knowledge of the world of ceramic technology. I really appreciated the community that makes up the School of Art in Dunedin who gave me this huge opportunity to grow as a visual artist and as a person.

Max Sepulveda is a prolific cross-disciplinary artist in the fields of audio-visual, pottery, textiles, printmaking and mural painting. Initially training in Chile, Argentina and Mexico, he studied Textile Design at the Iberoamerican Univerisity in Mexico City, where he also presented workshops and seminars. As an active practitioner for 20 years, he has worked with communities in different Chilean regions, Costa Rica, Mexico, Colombia and Uruguay. He conceives community art as a powerful tool for social transformation, therapy and nourishment. His work is inspired by place and embodies its natural and cultural heritage in order to visualize, appreciate, protect and revitalize local identity.

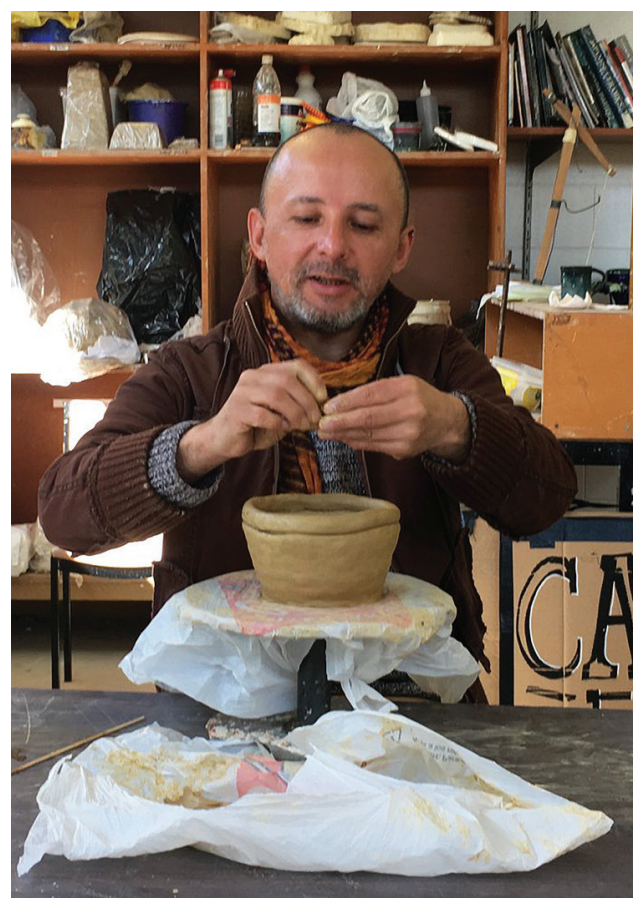

Max Sepulveda at work in the ceramics studio Dunedin School of Art. 